\title{
Transatlantica
}

Revue d'études américaines. American Studies Journal

\section{Paul Downes. Democracy, Revolution and Monarchism in Early American Literature.}

Cambridge : Cambridge UP, 2002. 239p.

Jean-Pierre Martin

\section{OpenEdition}

\section{Journals}

Édition électronique

URL : http://journals.openedition.org/transatlantica/813

DOI : $10.4000 /$ transatlantica.813

ISSN : 1765-2766

Éditeur

AFEA

Référence électronique

Jean-Pierre Martin, «Paul Downes. Democracy, Revolution and Monarchism in Early American

Literature. », Transatlantica [En ligne], 1 | 2005, mis en ligne le 22 avril 2006, consulté le 29 avril 2021

URL : http://journals.openedition.org/transatlantica/813; DOI : https://doi.org/10.4000/transatlantica. 813

Ce document a été généré automatiquement le 29 avril 2021.

\section{(c) (i) (9)}

Transatlantica - Revue d'études américaines est mis à disposition selon les termes de la licence Creative Commons Attribution - Pas d'Utilisation Commerciale - Pas de Modification 4.0 International. 


\section{Paul Downes. Democracy, Revolution and Monarchism in Early American Literature.}

Cambridge : Cambridge UP, 2002. 239p.

Jean-Pierre Martin

1 L'auteur, Associate Professor, Department of English, University of Toronto, part implicitement d'une évidence : pour l'ensemble hétérogène des colonies américaines rebelles, le lien à la Couronne est le seul commun dénominateur, et le trajet le plus court de Charleston à Boston passe par Londres...D'où, pour un tiers environ de la population - les Loyalistes - une fidèlité à la monarchie poussée parfois jusqu'à l'exil volontaire; mais pour les Indépendantistes, nolentes volentes, des références et des emprunts constants au système qu'ils abolissent. Truisme, certes, mais que Downes explore et illustre avec une acuité érudite: "The American Revolution's crucial opposition between monarchism and democracy cannot be disentangled [...] from the revolution's immediate reincorporation, by way of translation and displacement, of the structures and aporias of monarchism» (Introduction, 57). Thèse développée en cinq chapitres qui combinent heureusement histoire politique et incarnation littéraire de telle de ses composantes dans une œuvre de l'époque. Ainsi l'explosion antimonarchique de 1776 voit Freneau, Paine, et autres patriotes, multiplier les références à une couronne dans laquelle Emerson, cinquante ans plus tard, découvrira l'annonce "hiéroglyphique» des droits de l'homme (40)... Crèvecoeur, héraut de l'homme nouveau, déplore cette «malheureuse révolution » et l'instauration d'une république qui étouffera les singularités individuelles (chapitre 2) - thème que reprennent deux contemporains paradoxalement réunis, Stephen Burroughs, escroc, auteur de Memoirs, et Benjamin Franklin (chapitre 3): le premier dénonçant les rigueurs d'une loi abstraite, le second se félicitant au contraire de l'unanimité républicaine (il s'agit plus précisément du vote final de la Constitution par les conventionnels de Philadelphie). Autre legs de la monarchie, le culte du secret (chapitre 4) : Jefferson le dénonce, John Adams y voit le moyen d'assurer, sous les dehors de la souveraineté populaire, le pouvoir exclusif de l'élite - et Charles Brockden Brown en fait le ressort majeur de son 
œuvre romanesque (comme, parfois, James Fenimore Cooper dont un appendice analyse The Spy). Mais l'Indépendance a-t-elle eu lieu? ou la démocratie annoncée n'est-elle qu'une nouvelle version de ce babillage femelle qui chasse Rip Van Winkle dans les collines et n'offre à son réveil qu'une réalité peu plausible (chapitre 5) ?

2 L'on goûtera le registre des notations, tant historiques que littéraires et critiques, et une agilité intellectuelle parfois déconcertante. Mais il doit être possible d'écrire plus simplement... Au total, l'objection majeure à cet ouvrage ingénieux et pénétrant concernerait son titre, et l'emploi systématique du même vocable tout au long des analyses: comme tant d'auteurs américains, et autres, Paul Downes confond démocratie et forme républicaine de gouvernement. Jamais la coalition fédéraliste des « riches et bien nés » n'entendit instaurer la bellua multoru capitu.

INDEX

Thèmes : Recensions

\section{AUTEUR}

JEAN-PIERRE MARTIN

Université de Provence 